\title{
Microstructure of the Nickel-Base Superalloy CMSX-4 Fabricated by Selective Electron Beam Melting
}

\begin{abstract}
MARKUS RAMSPERGER, ROBERT F. SINGER, and CAROLIN KÖRNER
Powder bed-based additive manufacturing (AM) processes are characterized by very hightemperature gradients and solidification rates. These conditions lead to microstructures orders of magnitude smaller than in conventional casting processes. Especially in the field of high performance alloys, like nickel-base superalloys, this opens new opportunities for homogenization and alloy development. Nevertheless, the high susceptibility to cracking of precipitation-hardenable superalloys is a challenge for AM. In this study, electron beam-based AM is used to fabricate samples from gas-atomized pre-alloyed CMSX-4 powder. The influence of the processing strategy on crack formation is investigated. The samples are characterized by optical and SEM microscopy and analyzed by microprobe analysis. Differential scanning calorimetry is used to demonstrate the effect of the fine microstructure on characteristic temperatures. In addition, in situ heat treatment effects are investigated.
\end{abstract}

DOI: $10.1007 / \mathrm{s} 11661-015-3300-\mathrm{y}$

(c) The Author(s) 2016. This article is published with open access at Springerlink.com

\section{INTRODUCTION}

SINGLE-CRYSTAL nickel-base superalloys are well known for their extraordinary high-temperature properties. Thus, these alloys are widely used in the aerospace industry for turbine blades and vanes in the hot section of today's gas turbine engines.

CMSX-4 is a second generation single-crystal superalloy containing $3 \mathrm{wt}$ pct Re. This alloy is derived from CMSX-2, employing the beneficial strengthening effects of Re. It was established in the early 1990s and is used for single-crystalline turbine blades. Single-crystalline CMSX-4 is typically fabricated via investment casting and has been extensively developed to enhance the high-temperature properties. In addition, the microstructure is optimized by special heat treatments. After the conventional process route, it is not possible to dissolve the residual microsegregation in an economic way. ${ }^{[1]}$ The alloy provides good high-temperature properties due to the two-phase $\gamma / \gamma^{\prime}$-microstructure, a high volume fraction of $\gamma^{\prime}$ (up to $70 \mathrm{pct}$ ) and the solid solution strengthening effects of $\mathrm{Cr}, \mathrm{W}, \mathrm{Ta}$, and $\mathrm{Re}$. Additionally, Re decreases significantly the $\gamma^{\prime}$ coarsening kinetics. ${ }^{[2]}$ CMSX-4 also enhances oxidation resistance due to the reduced level of $\mathrm{Cr}$ and an increased level of Al $\left(\mathrm{Al}_{2} \mathrm{O}_{3}\right.$ former, more stable than $\mathrm{Cr}_{2} \mathrm{O}_{3}$ at high temperatures).

MARKUS RAMSPERGER, Research Associate, ROBERT $F$. SINGER, Professor, and CAROLIN KÖRNER, Professor and Head of Institute, are with the Department of Materials Science, Chair of Metals Science and Technology, University of Erlangen-Nuremberg, Martensstraße 5, 91058 Erlangen, Germany. Contact e-mail: markus. ramsperger@zmp.uni-erlangen.de

Manuscript submitted January 19, 2015.

Article published online January 6, 2016
In the as-cast condition, the microstructure of CMSX-4 shows a dendritic pattern with a $\gamma / \gamma^{\prime}$-eutectic in between (Figure 1). Segregation is caused by constitutional undercooling during solidification. Typically, $\gamma$ stabilizers like the refractory metals $\mathrm{W}, \mathrm{Co}$, and Re segregate within dendrite core areas, whereas $\gamma^{\prime}$ stabilizers like $\mathrm{Al}, \mathrm{Ti}$, and $\mathrm{Ta}$ accumulate within interdendritic areas. ${ }^{[3,4]}$ Thus, the cubic $\gamma^{\prime}$ precipitates are smaller within the dendritic core regions and become coarser near the interdendritic areas (eutectic regions) (Figure 1(c)) due to the increased amount of $\gamma^{\prime}$ stabilizers. ${ }^{[5]}$ Due to the inhomogeneous $\gamma^{\prime}$-distribution and remaining $\gamma / \gamma^{\prime}$-eutectic, great efforts with respect to time-consuming heat treatments have been undertaken to homogenize the microstructure in order to improve the high-temperature properties.

Usually, specific heat treatments for $\gamma^{\prime}$-precipitation and aging are performed after homogenization to reach the optimal $\gamma^{\prime}$ size and cubical morphology. ${ }^{[1,6]}$

An important criterion for heat treatment is the primary dendrite arm spacing (DAS) $\lambda_{1}$ which represents the length scale of element segregation. With increasing DAS, homogenization heat treatment gets more and more difficult and time-consuming. The refractory metals, especially Re, play an important role due to their very low diffusion coefficients in $\mathrm{Ni}\left(10^{-14}\right.$ to $10^{-16} \mathrm{~m}^{2} / \mathrm{s}$ ) in the temperature range of $1423 \mathrm{~K}$ to $1623 \mathrm{~K} \quad\left(1150{ }^{\circ} \mathrm{C}\right.$ to $\left.1350{ }^{\circ} \mathrm{C}\right) \cdot{ }^{[7,8]} \quad$ Furthermore, long-time heat treatments are necessary for a sufficient homogenization. Reducing the DAS results not only in a shorter and easier heat treatment procedure but is also expected to improve material properties.

The resulting DAS of the solidification microstructure can be strongly reduced (by a factor of two) by applying liquid metal cooling (LMC) or downward directional solidification process due to the higher temperature 

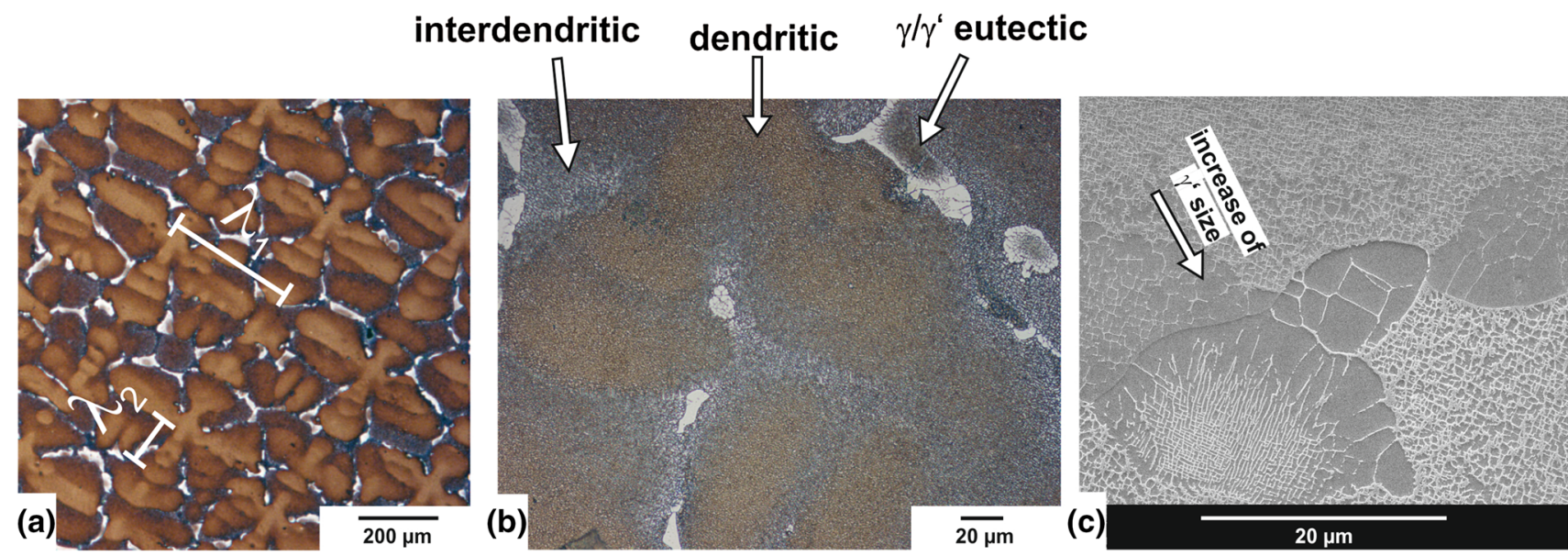

Fig. 1-Optical and SEM micrographs of an as-cast CMSX-4 sample (etched). (a) Dendritic pattern with the primary and secondary dendrite arm spacing $\lambda_{1}$ and $\lambda_{2}$, respectively, (b) dendrite core, interdendritic region and remaining $\gamma / \gamma^{\prime}$ eutectic, (c) SEM image of the interdendritic area.

gradients and solidification rates compared to radiation cooling. ${ }^{[9,10]}$ In order to reduce significantly the DAS, powder bed additive manufacturing (AM) is interesting because of the inherent high temperature gradients and solidification velocities. Up to now, most of the AM work concentrated on IN718, due to the good weldability. Selective electron beam melting (SEBM) work on IN718 was done by Helmer et al. ${ }^{[1]}$ where processing windows and microstructural properties were investigated. SEBM is a powder bed-based AM method where complex-shaped parts are built in layers of 50 to $100 \mu \mathrm{m}$ in a powder bed in vacuum at high temperatures. The need to work under vacuum conditions is an advantage because of the good powder protection from ambient atmosphere. Therefore, even strongly oxygen affine materials like Ti can be processed quite well. SEBM is characterized by a very high beam deflection speed of up to $8000 \mathrm{~m} / \mathrm{s}$ and a high usable beam power up to $3 \mathrm{~kW}$. High $\gamma^{\prime}$ volume fraction materials are susceptible to crack formation especially to strain age cracking and are typically considered as hard- or not weldable. ${ }^{[12-14]}$ Because of their high cracking susceptibility, it is a challenge to process materials like CMSX-4 by additive technologies. ${ }^{15,16]}$ In the literature, investigations on IN625, IN738, and Rene142 as representative materials with high $\gamma^{\prime}$ volume can be found. ${ }^{[17-19]}$ Mostly, the focus in these investigations is on the possibility to repair single-crystal turbine blades by welding. For implementing a material with a high $\gamma^{\prime}$ volume fraction by means of SEBM, only investigations on Rene142 are known. In that study, it is shown that the fabricated SEBM product behaves quite ideally with regard to potential creep-related behavior in turbine blade applications without any post-heat treatment. This can be explained by the columnar-grained microstructure of Rene142 developing during SEBM fabrication. ${ }^{[19]}$

Since SEBM can be considered as a continuous welding process, weldability is a good indicator for the processability, together of materials by SEBM.

Gäumann et al. ${ }^{[20]}$ investigate epitaxial laser metal forming of CMSX-4. They show that AM is an interesting technique for local repairs on single crystals
Table I. Chemical Composition of CMSX-4 Bar Stocks and Atomized Powder (Weight Percent)

\begin{tabular}{lcc}
\hline Element & CMSX-4 Bar & CMSX-4 Powder \\
\hline Cobalt & 9.60 & 9.80 \\
Tantalum & 6.50 & 6.40 \\
Chromium & 6.40 & 6.50 \\
Tungsten & 6.40 & 6.40 \\
Aluminum & 5.60 & 5.70 \\
Rhenium & 2.90 & 2.80 \\
Titanium & 1.01 & 0.97 \\
Molybdenum & 0.60 & 0.62 \\
Hafnium & 0.10 & 0.086 \\
Nickel & balance & balance \\
\hline
\end{tabular}

which combines the advantages of near-net-shape manufacturing and a close control of the microstructure, but no attempts were made to fabricate bulk samples.

In this contribution, the possibility to fabricate CMSX-4 by SEBM is investigated. By an appropriate processing strategy, dense and crack-free samples can be realized. Optical microscopy (OM) and scanning electron microscopy (SEM) are utilized to provide a comprehensive microstructural overview. These observations along with complementary microprobe (EPMA) element mappings and differential scanning calorimetry (DSC) measurements provide novel insights into the prospects for the production of complex CMSX-4 superalloy components by SEBM.

\section{EXPERIMENTAL APPROACH}

\section{A. Powder}

The prealloyed bar stocks were provided by Cannon Muskegeon Group, and the material was EIGA atomized (electrode induction-melting gas atomization) with argon at TLS Technik GmbH \& Co. Spezialpulver KG. The chemical composition of the master melt and the atomized powder is given in Table I. Chemical analysis of the atomized powder was performed with the 
induction coupled plasma method and is within the specification of Cannon Muskegon Group for CMSX-4 with a very low impurity level and a low oxygen content.

This crucible-free vacuum atomization process leads to a high powder quality since oxidation is minimized. The powder and particles are shown in Figure 2, respectively. Most of the particles are spherical, but there are also some irregular-shaped particles and some satellites, Figure 2 (left). Due to the rapid solidification during atomization, the microstructure of the particles is very fine and homogeneous, Figure 2 (right).

In this work, we used round-shaped powder particles with a particle size distribution between 45 and $105 \mu \mathrm{m}$. The particle size distribution was measured with a Mastersizer 3000 by laser diffraction technology and the key parameters were: $D_{10}=44.1 \mu \mathrm{m}, D_{50}=64.3 \mu \mathrm{m}$, $D_{90}=91.0 \mu \mathrm{m}$. The flowability and relative powder density were determined, based on DIN ISO 4490, with a bulk density of 56 pet and a flow time of the CMSX-4 powder $(50 \mathrm{~g})$ through a $2.54 \mathrm{~mm}$ notch of $21.3 \pm 0.3$ seconds. Both values are excellent for SEBM. Thus, the presence of the small amount of satellites does not strongly reduce the flowability.

\section{B. Sample Preparation}

The powder was processed in an ARCAM A2 EBM system operating at $60 \mathrm{kV}$ accelerating voltage in a controlled $10^{-3}$ mbar helium atmosphere. Maximum build size of this system can be up to $200 \times$ $200 \times 350 \mathrm{~mm}^{3}$. We used a target operating temperature above $1223 \mathrm{~K}\left(950{ }^{\circ} \mathrm{C}\right)$ and a constant layer thickness of $50 \mu \mathrm{m}$.

The SEBM process cycle can be divided into four steps. ${ }^{[21,22]}$ In the first step, a new powder layer is applied with a rake system. In the second step, the powder is preheated and slightly sintered to increase mechanical stability and electrical conductivity of the layer. During that sintering process, a strong defocused electron beam which scans the build area several times at a very high scan speed (up to $25000 \mathrm{~mm} / \mathrm{s}$ ) is used. The preheating parameters are chosen in such a way that the operating temperature is kept above $1223 \mathrm{~K}\left(950{ }^{\circ} \mathrm{C}\right)$ and on a constant level. Preheating is crucial since superalloys like CMSX-4 are very hard to sinter due to the formation of a stable $\mathrm{Al}_{2} \mathrm{O}_{3}$-oxide layer on the particle surface. During step 3, the powder is selectively melted by means of a focused electron beam which fuses to underlying material. The geometric data are given to the machine in the form of 2D layer information extracted from 3D CAD models. In the last step (step 4), the build platform is lowered and the process cycle begins again with the deposition of a new powder layer.

A design of experiment (DOE) for crack investigation/prevention was established in this work where 27 cubical samples with dimensions of $15 \times 15 \times 20 \mathrm{~mm}^{3}$ were built on a start plate with columnar supports. From the DOE, also an investigation about occurring binding faults in the samples was performed. The samples were produced by a line order hatching strategy, where the beam scans the melting area of the block in a snake-like way with a specific distance between the melting tracks (line offset) and in a specific line order*.

\footnotetext{
*The line order denotes the sequence in which the melting tracks are molten.
}

No contour melting was applied. A schematic for the scan strategy is depicted in Figure 3, left. For the DOE beam power, scan velocity and build temperature were varied and a line order of 5 was used.

To get information about the influence of stresses on the crack behavior, upside down pyramids with different geometries were built at two different build temperatures using constant process parameters. That experiment identifies the maximum possible melting area/diameter and crack initiation height for different stress states.

From the DOE, an optimum parameter set could be calculated. With this optimum parameter set, crack-free samples with a diameter of $\varnothing 12 \mathrm{~mm}$ and a height of 25 $\mathrm{mm}$ were produced in a separate build for microstructure investigations.
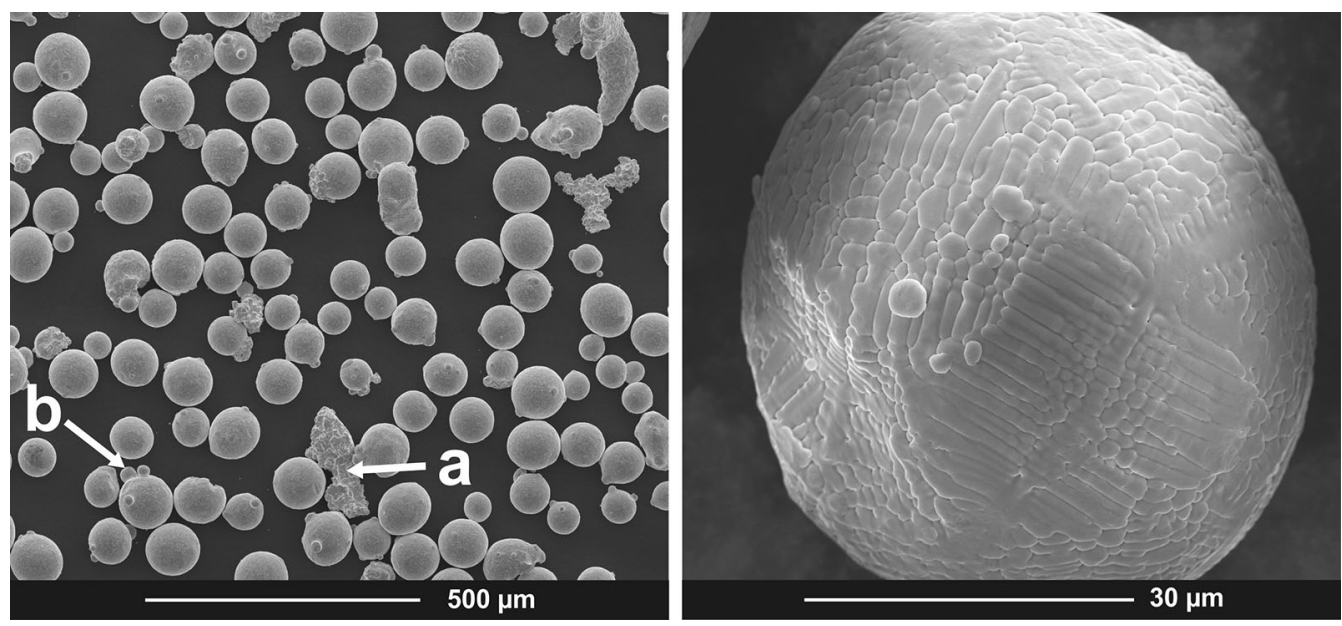

Fig. 2-EIGA atomized CMSX-4 (SEM). Left: Powder particles with some irregular-shaped particles $(a)$ and some satellites $(b)$ sticking on particles. Right: Particle surface with dendritic solidification structure. 

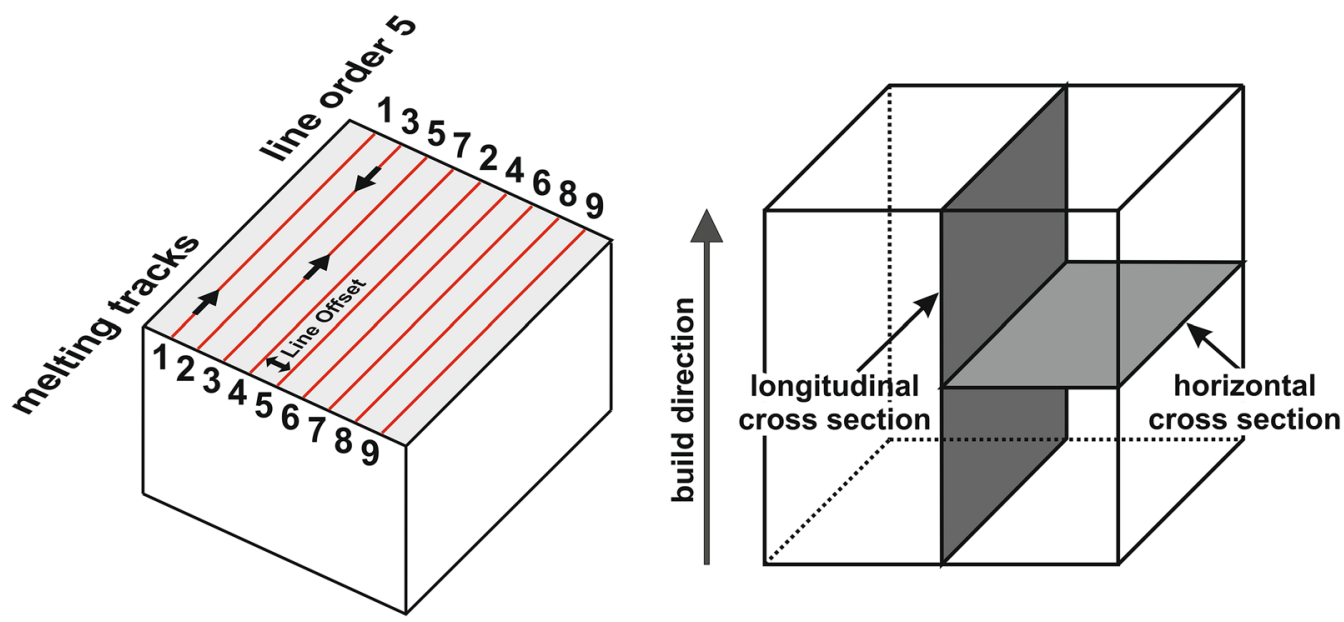

Fig. 3-Left: Schematic of the hatching strategy for a cubic sample. The line order indicates the chronological order of the melting tracks. The distance between the tracks is the line offset. Right: Longitudinal and horizontal cross section.
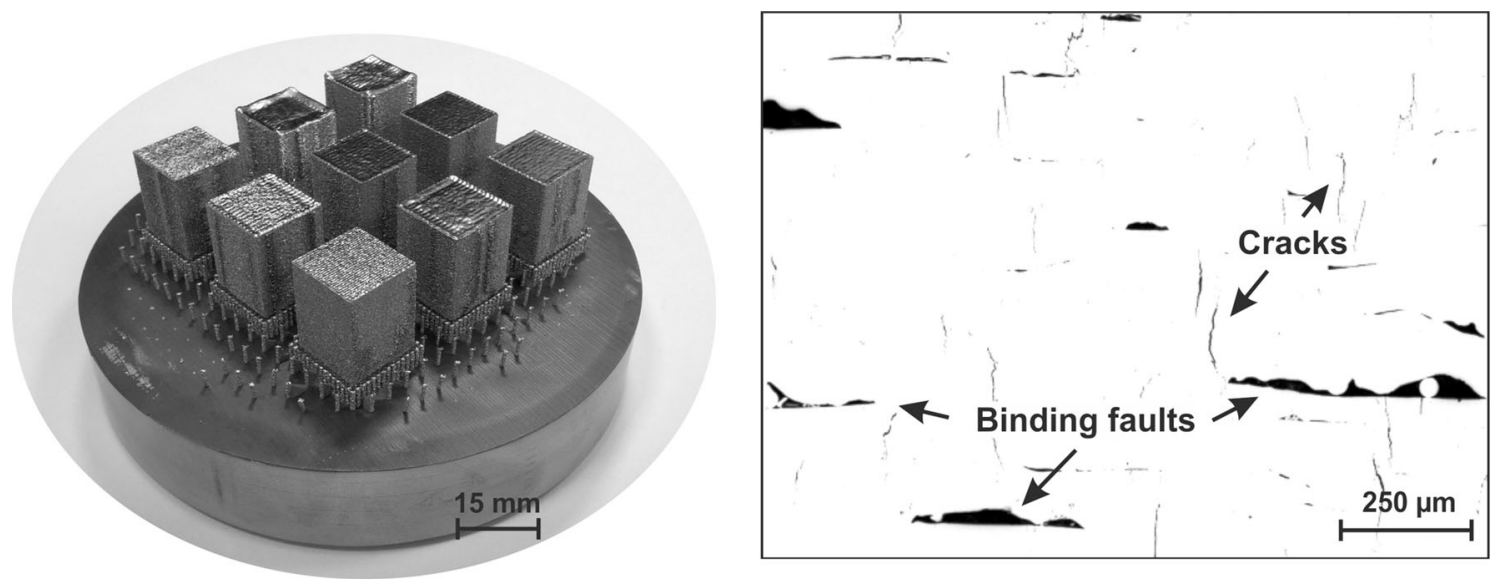

Fig. 4-DOE with nine cubic samples (left) and microstructure with cracks and binding faults (right).

The samples were investigated by optical microscopy (OM) utilizing Zeiss/Leica microscopes and digital imaging. The samples were cut in two cross sections (horizontal cross section/longitudinal cross section) and prepared with standard metallographic techniques. To highlight the microstructure samples were etched with a V2A etchant at $338 \mathrm{~K}$ to $343 \mathrm{~K}\left(65\right.$ to $\left.70{ }^{\circ} \mathrm{C}\right)\left(100 \mathrm{~cm}^{3}\right.$ $\mathrm{HCl}, 100 \mathrm{~cm}^{3} \mathrm{H}_{2} \mathrm{O}, 10 \mathrm{~cm}^{3} \mathrm{HNO}_{3}, 0.2$ to $2 \mathrm{~cm}^{3} \mathrm{Dr}$. Vogels Sparbeize) which etches the present grain structure as well as the $\gamma^{\prime}$ precipitates leaving the surrounding $\gamma$ matrix. For the investigation of crack and binding faults, images with a magnification of $50 \times$ in polished condition were used, $5 \mathrm{~mm}$ below the top surface and $2 \mathrm{~mm}$ above the bottom, respectively. For each position five images through the sample were investigated. Binding faults occur when the energy input is too low for complete melting of the powder layer and therefore longitudinal pores remain (see Figure 4). The specific crack density (1/ $\mathrm{mm}$ ) and the binding faults (in area pct) of each image were calculated by using a Matlab script.
The DAS $\lambda_{1}$ was calculated by OM images in horizontal cross sections as well according to the following equation:

$$
\lambda_{1}:=\sqrt{\frac{A}{N}}
$$

where $A$ is the area of the sample in the micrograph and $\mathrm{N}$ is the number of dendrites in the area. We apply this at three places in 1, 5, 10 and $15 \mathrm{~mm}$ below the sample top surface.

At each height four locations in the middle of the sample were analyzed. To investigate the $\gamma / \gamma^{\prime}$ microstructure SEM imaging (FEI Quanta 450 system) was used. The size and volume fraction of the $\gamma^{\prime}$ precipitates were determined by the Fullman Intercept Method at the same horizontal cross sections which were used for DAS calculations. ${ }^{[23]}$ Microprobe investigations with a JEOL JXA-8100 system were performed to examine element segregations within the samples. DSC analysis with a 

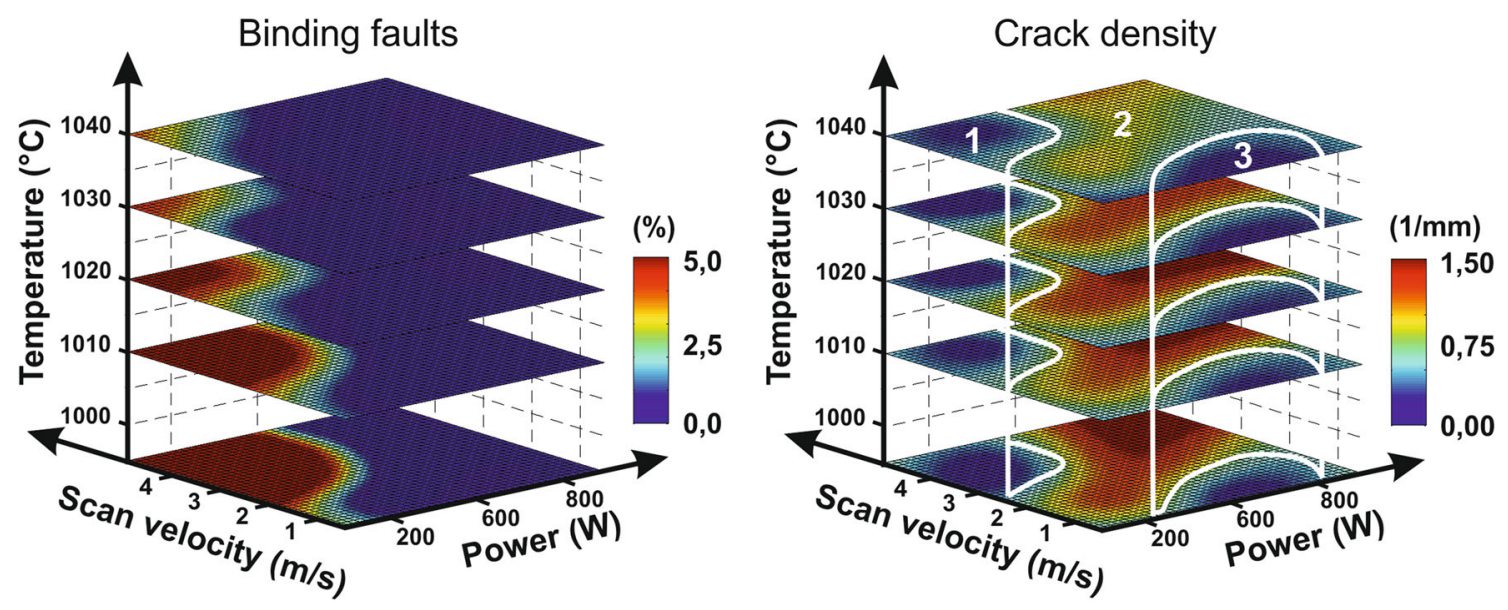

Fig. 5-DOE experiment, where the power, scan velocity, and the temperature were varied. Left: DOE for binding faults. Right: DOE for crack density.

heating rate of $5 \mathrm{~K} / \mathrm{min}$ was performed with a Netzsch STA409.

\section{RESULTS}

Figure 4 shows a typical start plate with cubic samples built on columnar supports with parameters chosen by DOE.

The results of the DOE for individual binding faults and crack densities are displayed in Figure 5. From the diagrams, it is evident that binding faults can be eliminated either by increasing the power or degreasing the velocity, leading to a higher energy input. The amount of binding faults decreases with increasing the temperature. This has to be taken into account regarding Area 1 at the crack density diagram. In Figure 5, three specific areas can be found. Area 1 indicates that there is a crack-free area on the left side. But in this area, the degree of binding faults is the highest. In Area 2, a high crack density can be found. Nevertheless, a reduction of the crack density by increasing the temperature can be found in dependence of the temperature. Crack-free parts can be achieved by using low scan velocities and at high beam power, related to Area 3.

The results from the pyramid experiment are shown in Figure 6. The main process parameters are: $P=300 \mathrm{~W}$, $v=500 \mathrm{~mm} / \mathrm{s}$ and line order $=5$. At lower build temperature $\left(\mathrm{T} 1=1213 \mathrm{~K} \quad\left(940{ }^{\circ} \mathrm{C}\right)\right)$, independent from the pyramid geometry, a maximum diameter without cracks between 5 and $7 \mathrm{~mm}$ is possible. The same experiment at higher temperature $(\mathrm{T} 2=1313 \mathrm{~K}$ $\left.\left(1040{ }^{\circ} \mathrm{C}\right)\right)$ shows no cracks in the pyramids and the maximum diameter $d_{2}$ is achieved.

An image section of a $12 \mathrm{~mm}$ diameter and $25 \mathrm{~mm}$ height sample produced according parameters to the DOE (Area 3) for crack-free samples is displayed in Figure 7. The sample shows in the polished longitudinal cross section no remaining cracks. Near the surface, the grain structure is polycrystalline and columnar in the core. The grains are mainly oriented parallel to the build direction and grow epitaxially across many layers.
Figure 8 shows a SEM image of an etched horizontal cross section with dendritic and interdendritic areas and grain boundaries. DAS investigation of the sample gives a value for $\lambda_{1}$ of $7.0 \pm 0.5 \mu \mathrm{m}$. The morphology of the solidification segregations (and therefore the different sizes of $\gamma^{\prime}$ ) is more cellular compared to conventional cast material. Only tiny remaining $\gamma / \gamma^{\prime}$-eutectics (about $2 \mu \mathrm{m})$ can be detected since the extension of the interdendritic area is similar to the size of the precipitates.

Figure 9 shows the regular $\gamma / \gamma^{\prime}$ microstructure in the dendritic region with the typical cuboidal-shaped $\gamma^{\prime}$ precipitates. The V2A etchant dissolves the $\gamma^{\prime}$-phase leaving the $\gamma^{\prime}$-matrix. Due to the high process temperatures, the precipitates grow during processing from $100 \pm 50 \mathrm{~nm}$ at $0.5 \mathrm{~mm}$ below the top surface to $380 \pm 50 \mathrm{~nm}$ at a distance of $15 \mathrm{~mm}$. The precipitates are homogeneously distributed in the matrix with a volume fraction of about $72 \pm 5$ pct independent from the sample height.

Element segregation has been analyzed by qualitative microprobe analysis of SEBM and commercial investment cast samples. The samples are produced with different process parameters to demonstrate their effect on the DAS. Figure 10 shows the results for the three representative elements $\mathrm{Ta}, \mathrm{W}$, and $\mathrm{Re}$, with very small diffusion coefficients making long solution heat treatments for homogenization necessary. The cast sample (Figure 10(a)) shows strong segregation with a DAS of about $300 \mu \mathrm{m}$. Ta segregates into interdendritic regions whereas $\mathrm{W}$ and $\mathrm{Re}$ accumulate in dendritic core.

Figure 10(b) is a zoom of Figure 10(a). The influence of process parameters on the microstructure is depicted in Figures 10(c) and (d). Sample (c) with a DAS of $6 \mu \mathrm{m}$ was built with high scan velocity and small line offset. A DAS of $3 \mu \mathrm{m}$ is presented in sample (d) built at slow scan velocity and high line offset. The latter parameter set leads to a smaller scale of segregations.

To investigate the segregation behavior in build direction over a multitude of layers also mappings in vertical cross sections were made, see Figure 11.

DSC-measurements were performed on heating condition in order to compare the thermal properties of cast 

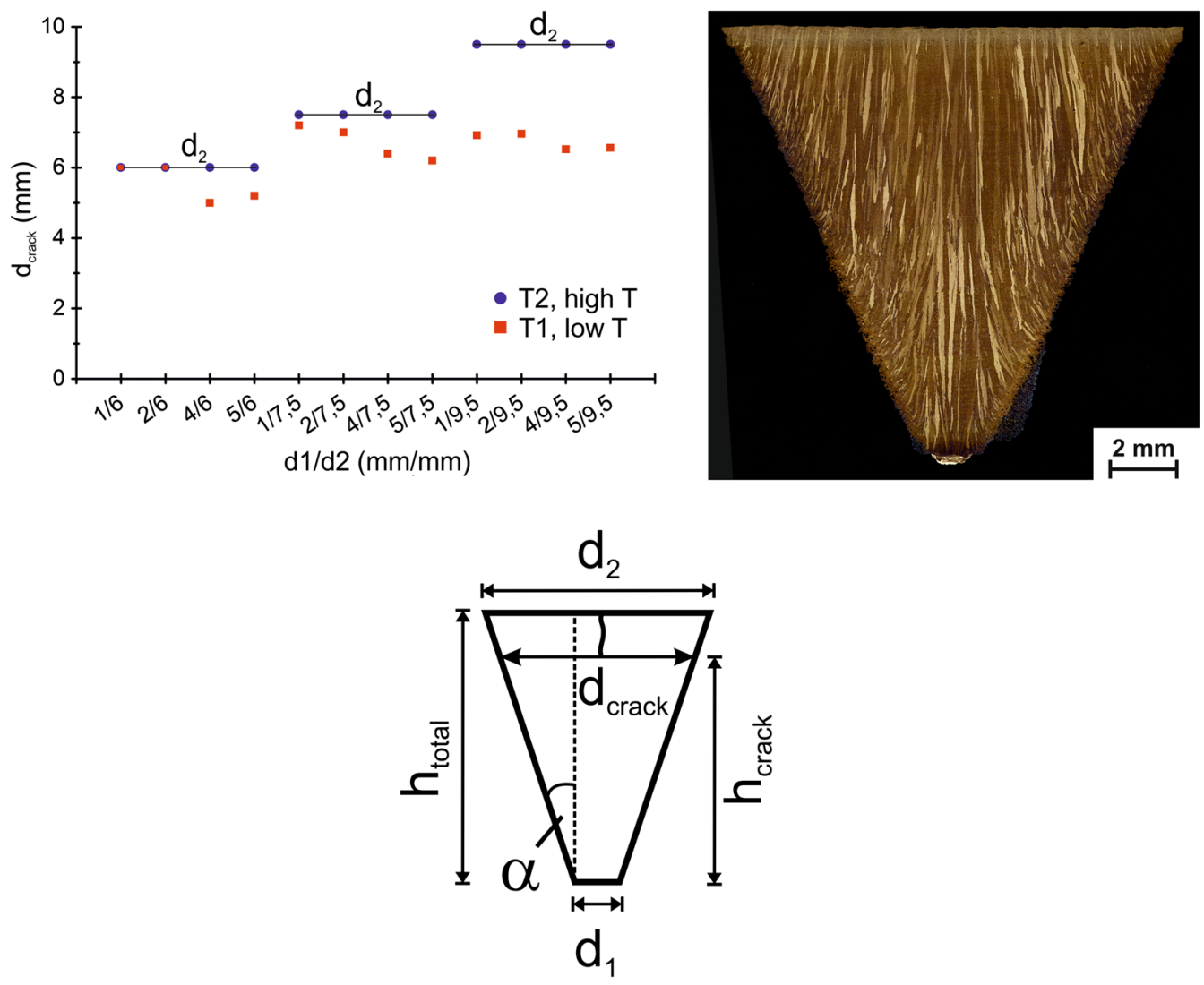

Fig. 6-Results from upside down pyramid experiment for crack investigation. The diagram shows the maximum diameter which can be realized without cracks.

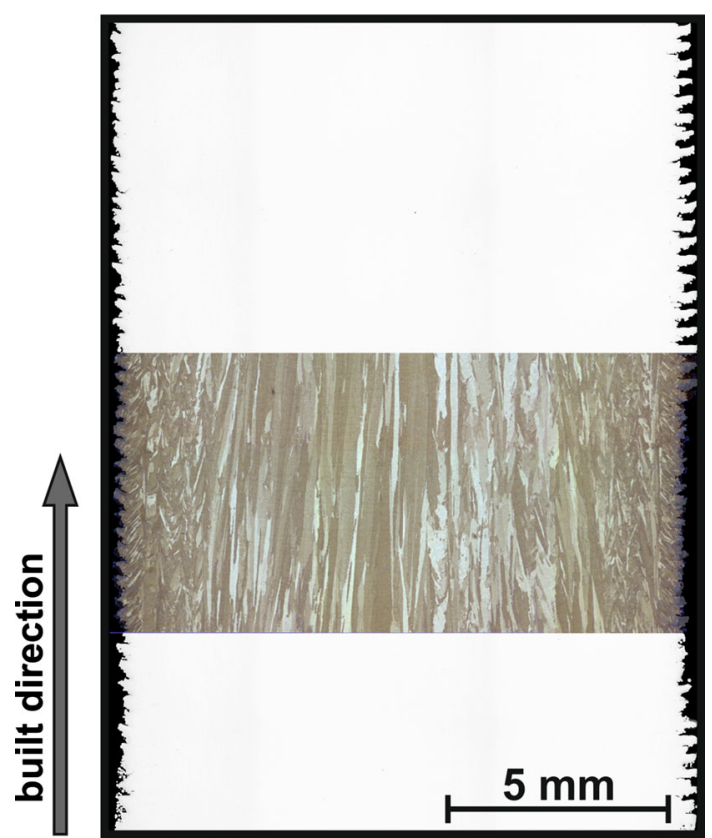

Fig. 7-OM image of a crack-free part in the polished condition (sample size $\varnothing 12 \mathrm{~mm}$ and a height of $25 \mathrm{~mm}$ ). An etched sequence is shown in which the present grain structure is visible.

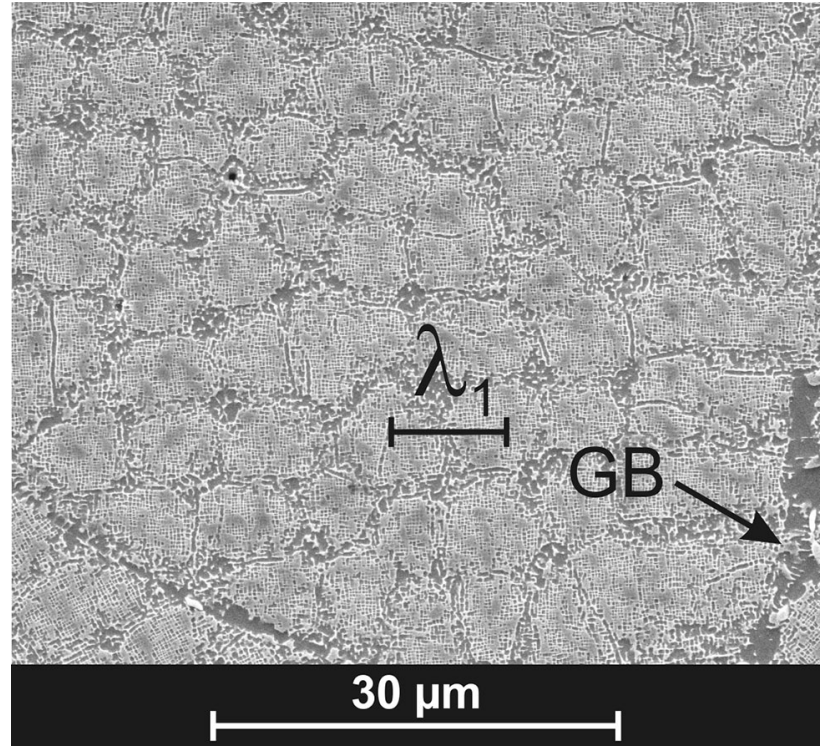

Fig. 8-Microstructure of SEBM sample in a distance of $5 \mathrm{~mm}$ from the top surface. (sample size $\varnothing 12 \mathrm{~mm}$ and a height of $25 \mathrm{~mm}$, horizontal cross section etched, SEM). Also grain boundaries with coarse $\gamma^{\prime}$ precipitates are obvious. 

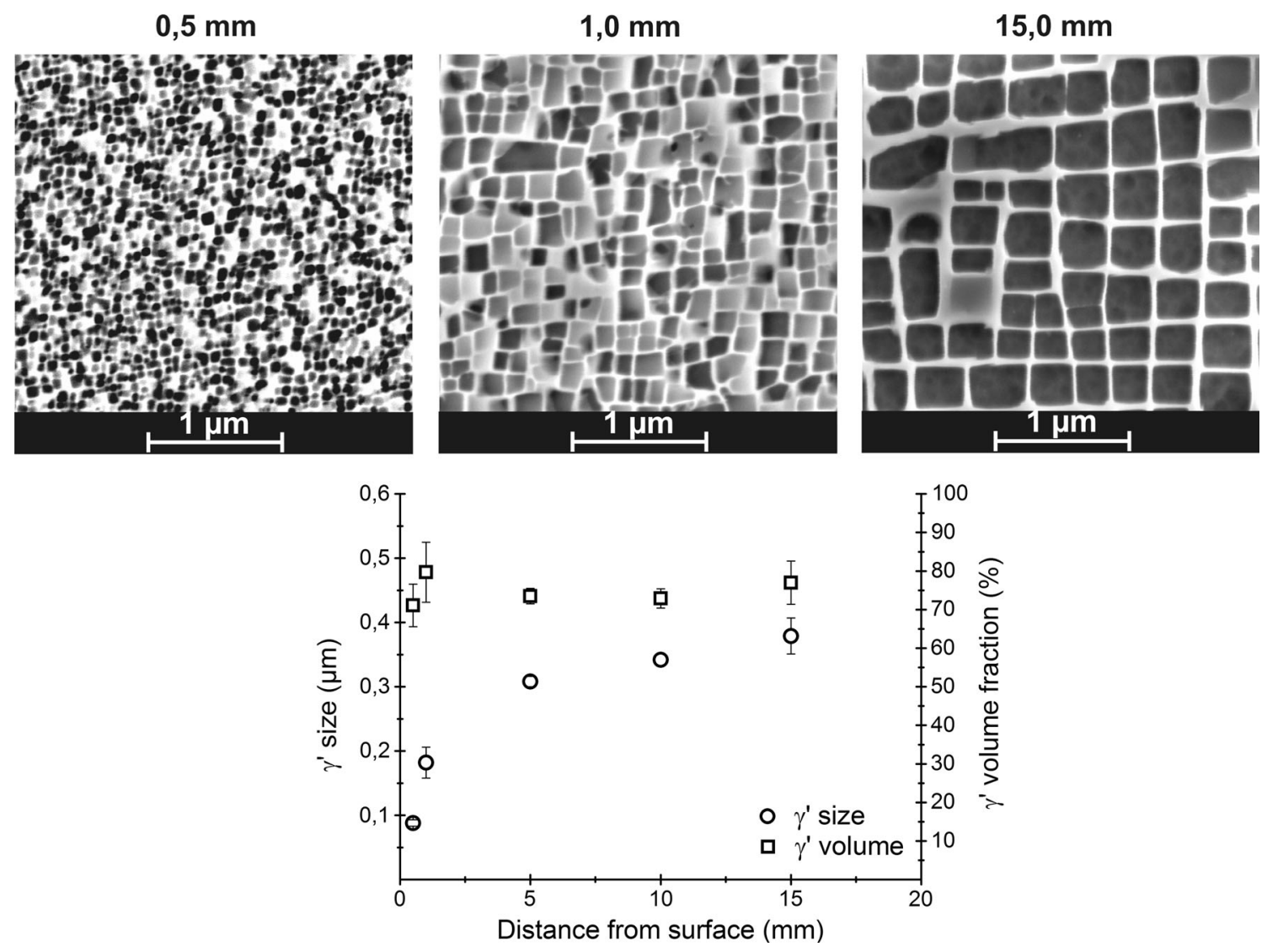

Fig. 9-SEM images of the SEBM $\gamma / \gamma^{\prime}$ microstructure at different sample heights. $\gamma^{\prime}$ size and volume as a function of the distance to the top surface (sample size $\varnothing 12 \mathrm{~mm}$ and a height of $25 \mathrm{~mm}$, horizontal cross section etched).

and SEBM samples, see Figure 12 and Table II. In conventionally cast CMSX-4, $T_{\text {solidus }}$ and $T_{\text {liquidus }}$ were determined (based on DIN 51007) to $1603 \mathrm{~K}$ and $1669 \mathrm{~K} \quad\left(1330{ }^{\circ} \mathrm{C}\right.$ and $\left.1396{ }^{\circ} \mathrm{C}\right)$, respectively. For SEBM CMSX-4, $T_{\text {solidus }}$ and $T_{\text {liquidus }}$ are $1619 \mathrm{~K}$ and $1667 \mathrm{~K}\left(1346{ }^{\circ} \mathrm{C}\right.$ and $\left.1394{ }^{\circ} \mathrm{C}\right)$, respectively. In addition to the melting peak, a second small endothermic signal related to the $\gamma^{\prime}$ dissolution appears at $1571 \mathrm{~K}$ $\left(1298^{\circ} \mathrm{C}\right)$. Furthermore, the SEBM sample shows a clear sink at the $\gamma^{\prime}$ solvus temperature and no $\gamma /$ $\gamma^{\prime}$ eutectic solution peak. For the cast sample, no $\gamma^{\prime}$ solvus temperature can be determined but a peak indicating the solution of the $\gamma / \gamma^{\prime}$ eutectic is visible.

\section{DISCUSSION}

\section{A. Crack Formation and Grain Microstructure}

As expected, CMSX-4 is hardly weldable due to strong crack formation during processing. These cracks are induced by stresses and thus dependent on the geometry of the sample. The correlation between crack formation and sample thickness is demonstrated with the pyramid experiment. To determine parameter sets where cracks do not occur a DOE approach was applied (Figures 5,6 and 7). The DOE shows that the build temperature has a strong influence on crack formation. Thus, very high temperatures are necessary for crack-free processing of
CMSX-4. Otherwise, only a specific diameter of the parts can be realized before cracks occurred.

The grain structures of the crack free samples are columnar in the core of the sample and more polycrystalline near the surface (Figures 6 and 7). The reason for equiaxed grains is grain nucleation from the surrounding powder bed during melting and solidification. The partially molten powder particles act as new grain nuclei and these nuclei grow and follow the direction of the temperature gradient $G$ and the solidification velocity $v$ at solidification front. In the core, $\mathrm{G}$ and $\mathrm{v}$ are parallel to the build direction and epitaxial columnar grain growth across several layers is observed.

\section{B. Primary Dendrite Arm Spacing and Element Segregation}

SEBM results in a significant reduced primary DAS compared to conventional castings (Figure 10). Thus, also the segregation scale is on an up to 100 time smaller scale than in conventional castings. Typical primary DAS is in the range of 200 to $500 \mu \mathrm{m}$ for conventional HRS and LMC processes, depending on the withdrawal rate, the temperature gradient, and the size and geometry of the cast samples. ${ }^{[9,10,24-26]}$ During SEBM, very high solidification velocities and temperature gradients are reached due to self-quenching. The primary DAS is correlated to $\mathrm{G}$ and v by ${ }^{[25]}$ 
image section

(a)
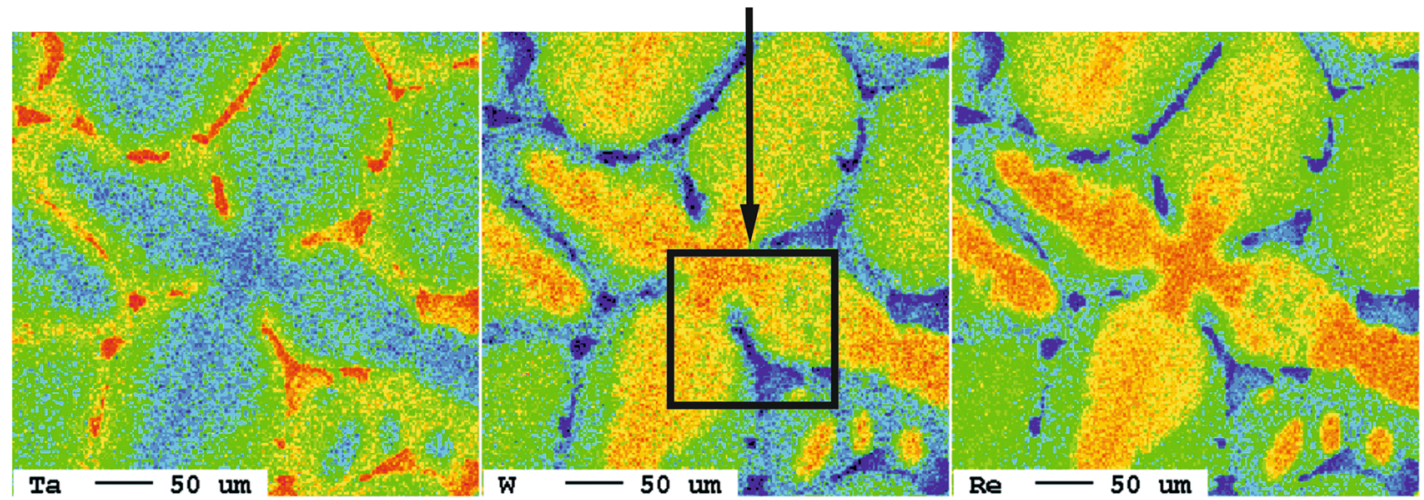

Ta Level

250
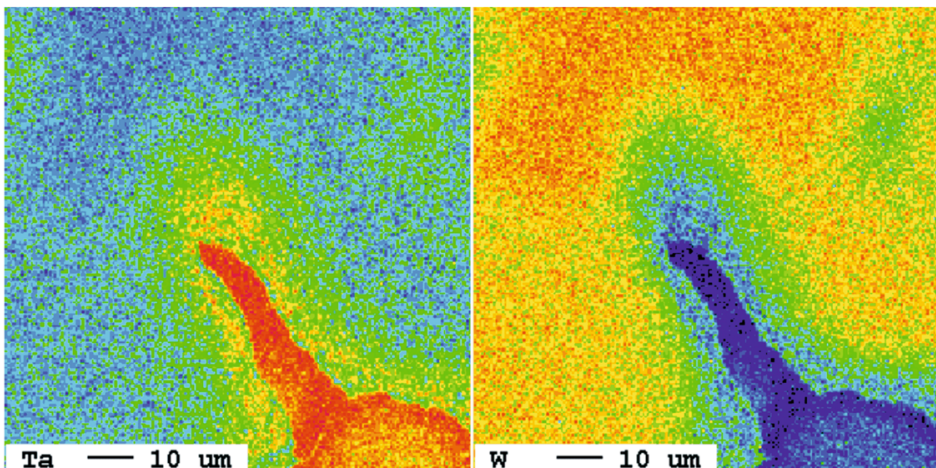

resch
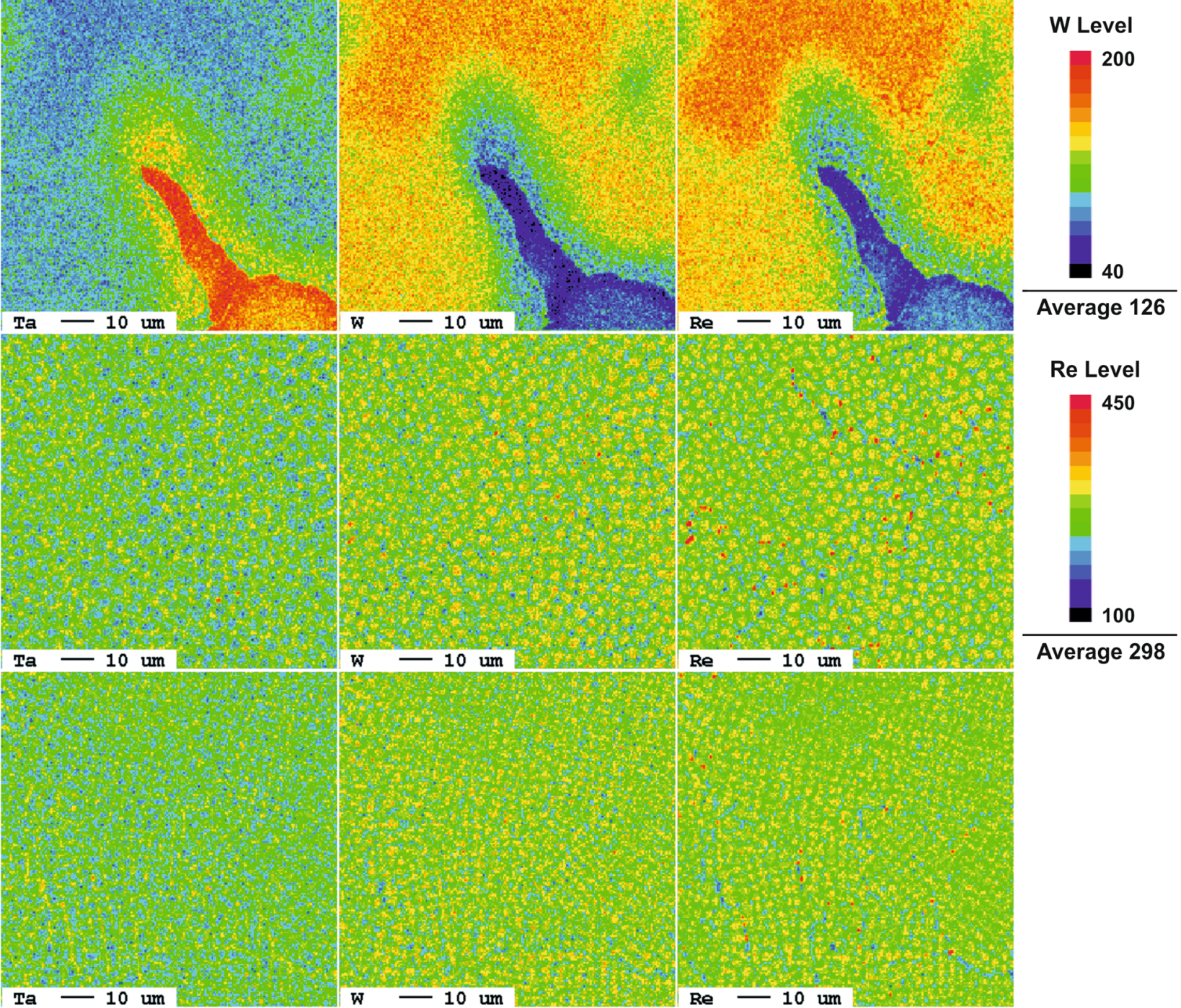

(d)

Fig. 10-Qualitative microprobe mappings (horizontal cross section) of Ta, W, and Re. (a) As-cast sample analyzed with a spot size of $2 \mu \mathrm{m}(b)$ Magnification of (a) (spot size $0.5 \mu \mathrm{m})($ c) SEBM sample $(P=510 \mathrm{~W}, v=6000 \mathrm{~mm} / \mathrm{s}$, line offset $=0.03 \mathrm{~mm})(\mathrm{spot}$ size $0.5 \mu \mathrm{m})(d)$ SEBM sample $(P=180 \mathrm{~W}, v=300 \mathrm{~mm} / \mathrm{s}$, line offset $=0.1 \mathrm{~mm})($ spot size $0.5 \mu \mathrm{m})$. 
(a)
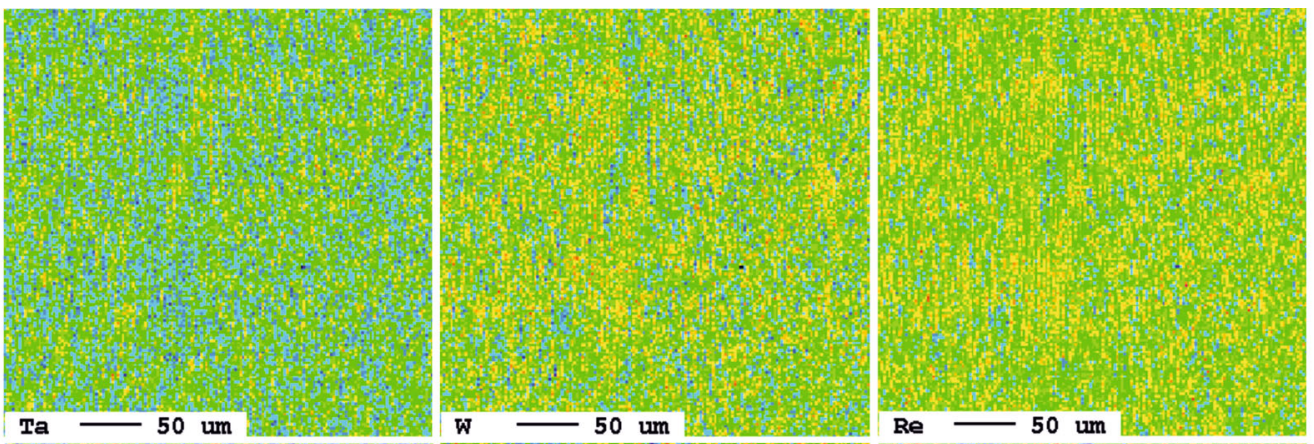

Ta Level
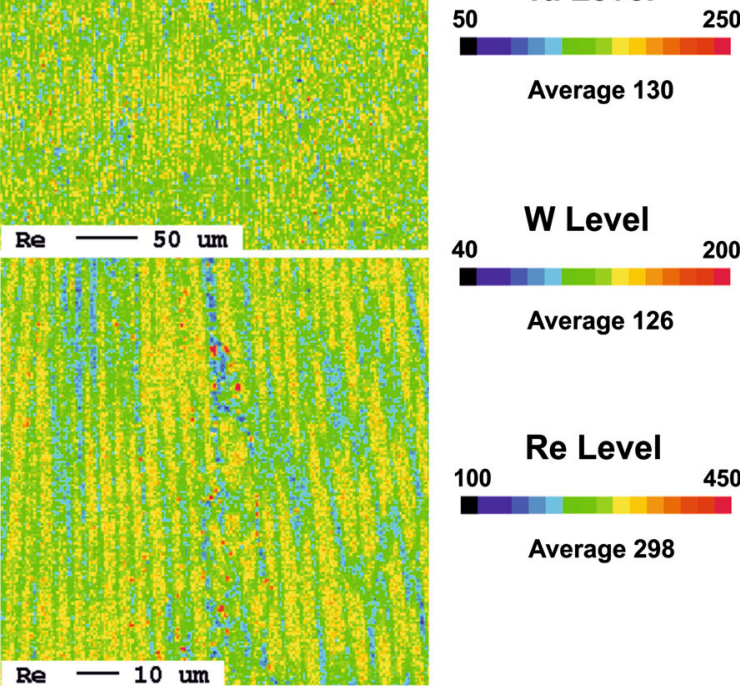

Average 126

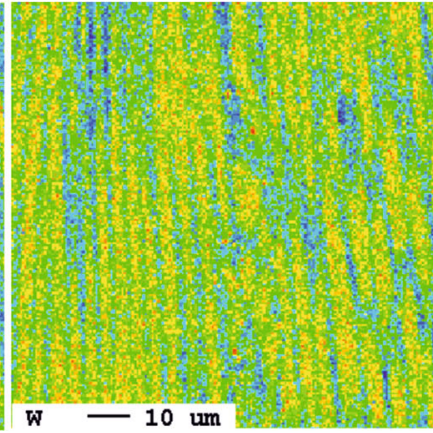

Re -10 um

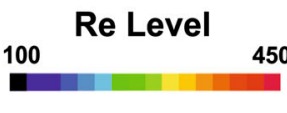

Average 298

Fig. 11-Qualitative microprobe mappings (vertical cross section) of Ta, W and Re of sample (c) in Fig 10. (a) Analyzing spot size: $2 \mu$ m, (b) analyzing spot size: $0.5 \mu \mathrm{m}$.

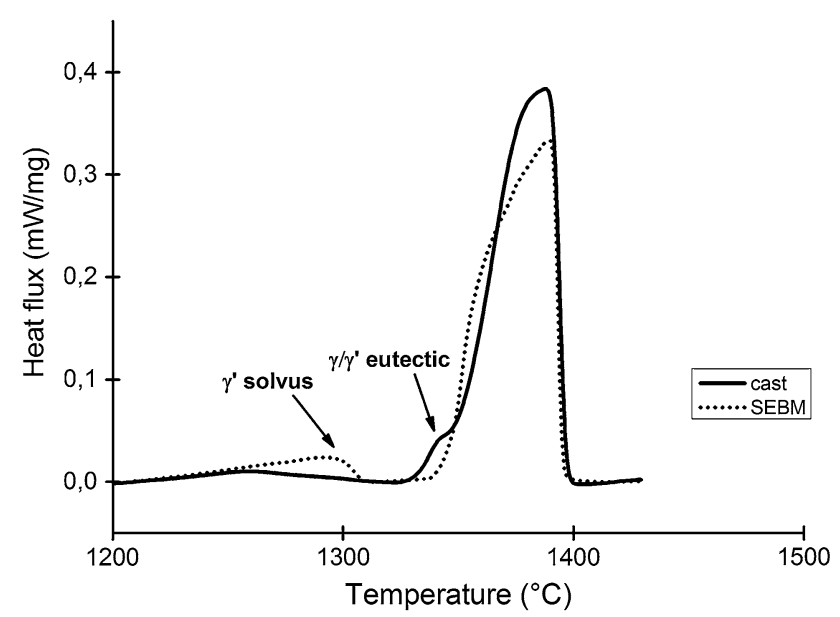

Fig. 12-DSC measurements of a conventionally cast sample and a SEBM as-built sample on heating $(5 \mathrm{~K} / \mathrm{min})$.

$$
\lambda_{1} \sim \frac{1}{G^{\frac{1}{2}}} \cdot \frac{1}{v^{\frac{1}{4}}}
$$

Thus, $\lambda_{1}$ conventional cast $\left(\lambda_{1}^{\text {con }}\right)$ and $\lambda_{1}$ SEBM $\left(\lambda_{1}^{\mathrm{SEBM}}\right)$ can be correlated by

$$
\frac{\lambda_{1}^{\text {con }}}{\lambda_{1}^{\mathrm{SEBM}}}=\left(\frac{G^{\mathrm{SEBM}}}{G^{\mathrm{con}}}\right)^{\frac{1}{2}} \cdot\left(\frac{v^{\mathrm{SEBM}}}{v^{\mathrm{con}}}\right)^{\frac{1}{4}}
$$

From casting of the reference material and unpublished simulation results of the SEBM, the following values for $\mathrm{G}$ and $\mathrm{v}$ are established and shown in Table III. ${ }^{[9,26]}$
From Eq. [3] and Table III the ratio $\frac{c_{1}^{\text {con }}}{\lambda_{1}^{\text {SEBM }}}$ is 93 . This is consistent with the experimental observation, that $\lambda_{1}^{\text {SEBM }}$ can be approximately up to two orders of magnitude smaller than $\lambda_{1}^{\text {con }}$. The extreme solidification conditions have an influence on the morphology of the microstructure. The dendrites are mainly cellular due to the high cooling rates which prevent secondary dendrite arm formation.

Microprobe cross section maps of the SEBM samples in Figures 10(c) and (d) and 11 show the distribution of the refractory elements on the scale of the DAS. Segregation behavior is on a sub-micrometer scale which is already smaller than the best spatial resolution of the microprobe of $0.5 \mu \mathrm{m}$. Thus, only qualitative results can be achieved. Information about exact maximum and minimum concentration values cannot be extracted. Differences between (c) and (d) are caused by the process parameters resulting in different solidification velocities and temperature gradients leading to different DAS, see Eq. [2]. Because of the small segregation scale, the time necessary for homogenization heat treatment is strongly reduced. Therefore, standard heat treatments for many hours can be replaced by heat treatments within minutes. ${ }^{[27]}$

Figures 11(e) and (f) show longitudinal cross section maps across many melting layers. There is no indication for local segregation effects in build direction.

\section{C. $\gamma / \gamma^{\prime}$ Microstructure and Coarsening}

Figure 1(c) shows qualitatively the characteristically $\gamma^{\prime}$ coarsening from the dendrite core to the interdendritic region and the remaining $\gamma / \gamma^{\prime}$ eutectic in an as-cast sample. SEBM samples have a high volume fraction of $\gamma^{\prime}$ precipitates, the typical cuboidal shape and show a 
Table II. DSC Analysis Values From Fig. 10

\begin{tabular}{lccc}
\hline Sample & $T_{\text {solidus }}$ & $T_{\text {liquidus }}$ & $T_{\gamma^{\prime} \text { solvus }}$ \\
\hline Cast CMSX-4 & $\sim 1603 \mathrm{~K}\left(1330{ }^{\circ} \mathrm{C}\right)$ & $\sim 1669 \mathrm{~K}\left(1396^{\circ} \mathrm{C}\right)$ & - \\
SEBM CMSX-4 & $\sim 1619 \mathrm{~K}\left(1346^{\circ} \mathrm{C}\right)$ & $\sim 1667 \mathrm{~K}\left(1394^{\circ} \mathrm{C}\right)$ & $\sim 1571 \mathrm{~K}\left(1298{ }^{\circ} \mathrm{C}\right)$ \\
\hline
\end{tabular}

Table III. Characteristic Values for $G$ and $v$ in Conventional Casting and SEBM, Respectively

\begin{tabular}{llr}
\hline & \multicolumn{1}{c}{ Conventional } & SEBM \\
\hline $\mathrm{G}$ & 1 to $4 \mathrm{~K} / \mathrm{mm}\left(1\right.$ to $\left.4{ }^{\circ} \mathrm{C} / \mathrm{mm}\right)$ & $200 \mathrm{~K} / \mathrm{mm}\left(200{ }^{\circ} \mathrm{C} / \mathrm{mm}\right)$ \\
$\mathrm{v}$ & 0.05 to $0.15 \mathrm{~mm} / \mathrm{s}$ & $20 \mathrm{~mm} / \mathrm{s}$ \\
\hline
\end{tabular}

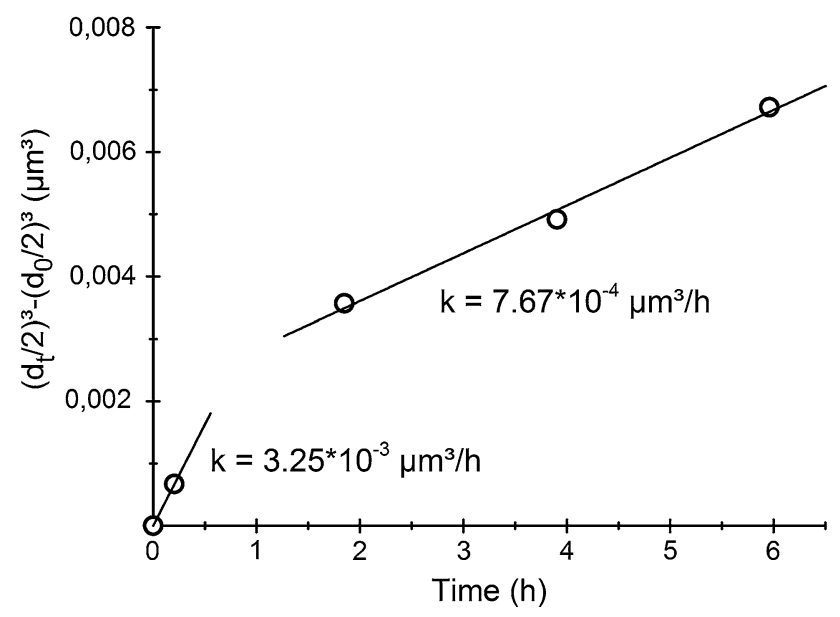

Fig. 13- Growth of the $\gamma^{\prime}$ precipitates during processing and calculation of the growth constant $k$.

time depending coarsening in the as-built condition (Figure 9). Another interesting observation is that only small-sized $\gamma / \gamma^{\prime}$ eutectics or coarse $\gamma^{\prime}$ particles in the interdendritic areas can be detected in the SEBM samples (Figure 8).

Both observations can also be explained by the fine microstructure and the small scale of segregation. Due to segregation, the local variation of the $\gamma^{\prime}$ sizes in cast material is caused by the inhomogeneous distribution of the $\gamma^{\prime}$ formers. In SEBM samples, the length scale on which segregation occurs is very small. Thus, the interdendritic area is very small and similar to the size of the $\gamma^{\prime}$ precipitates, see Figure 8 .

The Fullman Intercept Method which was used for size and volume fraction measurements was originally developed for round and not for cubic precipitates. Therefore, small differences in the results could occur. Comparative measurements show that the difference between the Fullman method and an exact calculation of the volume fraction is between 4 and 5 vol pct. Nevertheless, this method is a good method for size and volume fraction measurements and easy to handle. Figure 9 demonstrates the effect of the process-inherent in situ heat treatment during SEBM. Layers which are built at different heights are subjected to different heat treatments already during building. Thus, the local $\gamma^{\prime}$ size is a function of the position within the sample and the temperature. The $\gamma^{\prime}$ precipitates grow during the building process caused by the process temperature above $1223 \mathrm{~K}\left(950{ }^{\circ} \mathrm{C}\right)$. The precipitates at the bottom of the sample are therefore larger than those in regions near the top surface. The $\gamma^{\prime}$ coarsening can be described in a first-order approach by diffusion-controlled particle coarsening (the law of Lifshitz and Slyzov),

$$
\left(\frac{d_{t}}{2}\right)^{3}-\left(\frac{d_{0}}{2}\right)^{3}=k \cdot t
$$

where $d_{0}$ and $d_{\mathrm{t}}$ denote the average diameter of the $\gamma^{\prime}$ particles at time $=0$ and time $=t$, respectively, and $k$ is a temperature-dependent constant. ${ }^{[28]}$

Based on our experimental results (see Figure 9), the constant $\mathrm{k}$ for SEBM CMSX-4 can be estimated in Figure 13.

The results show that there are different growth regimes and therefore different $\mathrm{k}$. Near the surface, the temperature is still much higher than the building temperature which is approached in the sample after a while. For the first 10 layers $(0.5 \mathrm{~mm}, 0.2 \mathrm{~h})$, high $\mathrm{k}$ value of $3.25 \times 10^{-3} \mu \mathrm{m}^{3} / \mathrm{h}$ is determined. For longer times, $\mathrm{k}$ reduces to $7.67 \times 10^{-4} \mu \mathrm{m}^{3} / \mathrm{h}$. These values for $\mathrm{k}$ are somewhere higher compared to literature values from MacKay et al. ${ }^{[29]}$ where a quaternary Ni-based system Ni-6 wt pet Al-6 wt pet Ta-X wt pet Mo was investigated with $k$ values in the range of 2 to $18 \times 10^{-5} \mu \mathrm{m}^{3} / \mathrm{h}$ at $1255 \mathrm{~K}\left(982{ }^{\circ} \mathrm{C}\right)$ depending on the occurring lattice mismatch of $\gamma$ and $\gamma^{\prime}$ due to different Mo concentrations. The high value of $k$ for SEBM CMSX-4 can be explained by regarding two aspects. In the first 10 to 20 layers below the last melting layer, there are no stationary temperature conditions due to melting, re-melting, and heat-affected zones. Therefore, much higher temperatures are present in this area before a stationary temperature level is reached. As a consequence, faster growth of the precipitates occurs. Afterwards, more or less stationary temperature conditions in the SEBM process are achieved which were much higher than in the experiments of MacKay et al. ${ }^{[29]}$ The higher (stationary) temperatures in SEBM result in a higher value for $k$.

\section{Thermo-Analysis}

The DSC curves (Figure 12) show a significant difference between the as-cast and the as-built SEBM sample. In the as-cast material, the $\gamma^{\prime}$-solvus 
temperature can hardly be determined. The $\gamma^{\prime}$ precipitates dissolve in a wide temperature range between $1523 \mathrm{~K}$ and $1623 \mathrm{~K}\left(1250{ }^{\circ} \mathrm{C}\right.$ and $\left.1350{ }^{\circ} \mathrm{C}\right)$. The peak at the end of this temperature range indicates the dissolution of the $\gamma / \gamma^{\prime}$-eutectic phase. In the literature, it is shown that it is easier to determine the $\gamma^{\prime}$ solvus temperature for non-heat-treated material during cooling. ${ }^{30-32]}$ Nevertheless, since we want to characterize the behavior of the as-cast and as-built material during heat treatment heating conditions, the focus is on heating.

In contrast to the as-cast sample, the as-built SEBM sample shows a clear signal at a defined temperature interval of $20 \mathrm{~K}\left(20^{\circ} \mathrm{C}\right)$ from $1563 \mathrm{~K}$ to $1583 \mathrm{~K}$ $\left(1290{ }^{\circ} \mathrm{C}\right.$ to $\left.1310^{\circ} \mathrm{C}\right)$. A characteristic temperature of $1571 \mathrm{~K}\left(1298^{\circ} \mathrm{C}\right)$ can be identified as the $\gamma^{\prime}$-solvus temperature which corresponds to the $\gamma^{\prime}$-solvus temperature range for CMSX-4 known in the literature. ${ }^{[26]} \mathrm{A}$ typical peak for the dissolution of the $\gamma / \gamma^{\prime}$-eutectic is not present.

The main reason for this quite different behavior of the as-cast und as-built samples is again the different distributions of the alloying elements and the homogeneity. During heating the as-cast material, the smaller $\gamma^{\prime}$ precipitates in the dendrite core are the first to dissolve due to their high surface energy. At higher temperatures, the much larger $\gamma^{\prime}$ precipitates within the interdendritic regions start to dissolve. Finally, the $\gamma / \gamma^{\prime}$-eutectic with the largest $\gamma^{\prime}$ precipitates dissipates. Thus, strong element segregations present in the as-cast material lead to a wide range of the $\gamma^{\prime}$-solvus temperature. ${ }^{[26,32]}$

As a consequence of SEBM processing, size, distribution, and volume fraction of the $\gamma^{\prime}$ precipitates are very homogenous. A difference between the dendritic core and the interdendritic region is barely noticeable. Thus, a clear signal in the DSC curves appears indicating a very homogenous particle size and volume fraction. Besides this, SEBM samples show only very small $\gamma / \gamma^{\prime}$-eutectic regions compared to those in cast material. The small volume fraction of eutectic is the reason why a dissolution peak does not appear.

The DSC results also show that the solidus temperature of the SEBM samples is about $16 \mathrm{~K}\left(16{ }^{\circ} \mathrm{C}\right)$ higher than that of the cast material. Again, this behavior can be attributed to the more homogenous distribution of elements. Probably, the time which is necessary for heating up the samples should be sufficient to homogenize the material.

\section{CONCLUSIONS}

Selective electron beam melting is used to produce simple geometries out of the single-crystalline alloy CMSX-4. Even if this alloy has a high susceptibility for crack formation, crack-free samples can be realized by proper adjustment of the process temperature and processing parameters. The resulting microstructure is about two orders of magnitude smaller than in conventional castings. The extremely high homogeneity in the as-built state has strong influence on the size distribution of the $\gamma^{\prime}$ precipitates and increases the solidus temperature by $16 \mathrm{~K}\left(16^{\circ} \mathrm{C}\right)$. These findings make
SEBM a very promising approach for further investigations and open the possibility to produce defect-free and complex parts of high volume-fraction $\gamma^{\prime}$ alloys for application with such remarkable microstructural properties.

\section{ACKNOWLEDGMENTS}

The German Research Foundation (DFG) and the Collaborative Research Center 103 project B2 are thankfully acknowledged for the financial support. We also thank Sabine Michel for the microprobe mappings.

\section{OPEN ACCESS}

This article is distributed under the terms of the Creative Commons Attribution 4.0 International License (http://creativecommons.org/licenses/by/4.0/), which permits unrestricted use, distribution, and reproduction in any medium, provided you give appropriate credit to the original author(s) and the source, provide a link to the Creative Commons license, and indicate if changes were made.

\section{REFERENCES}

1. K. Harris, G.L. Erickson, S.L. Sikkenga and W.D. Brentnall: in Superalloys 1992, R.W. Stusrud S.D. Antolovich, R.A. MacKay, D.L. Anton, T. Khan, R.D. Kissinger, and D.L. Klarstrom, eds., The Minerals, Metals \& Materials Society, 1992, pp. 297-306.

2. A. Sengupta, S.K. Putatunda, J. Hangas, P.J.Nailos, M. Peputapeck, and F.E. Alberts: J. Mater. Eng. Perform., 1994, vol. 3, pp. 73-81.

3. S.N. Tewari, M. Vijayakumar, J.E. Lee, and P.A. Curreri: Mater. Sci. Eng. A, 1991, vol. 141, pp. 97-102.

4. D. Goldschmidt: Materialwissenschaft und Werkstofftechnik, 1994, vol. 25 , pp. 311-20.

5. B.C. Wilson, J.A. Hickman, and G.E. Fuchs: JOM, 2003, vol. 55, pp. $35-40$.

6. D. Goldschmidt: Materialwissenschaft und Werkstofftechnik, 1994, vol. 25 , pp. $373-82$.

7. M.S.A. Karunaratne, D.C. Cox, P. Carter and R.C. Reed: in Superalloys 2000, T.M. Pollock et al. eds., The Minerals, Metals \& Materials Society, Seven Springs, 2000, pp. 263-72.

8. A.I. Epishin, A.O. Rodin, B.S. Bokshtein, G. Oder, T. Link, and I.L. Svetlov: Phys. Metals Metallogr., 2015, vol. 116, pp. 175-81.

9. A. Lohmüller, W. Eßer, J. Großmann, M. Hördler, J. Preuhs and R.F. Singer: in Superalloys 2000, R.D. Kissinger T.M. Pollock, R.R. Bowmann, K.A. Green, M. McLean, S. Olsen, and J.J. Schirra, eds., The Minerals, Metals \& Materials Society, Seven Springs, 2000, pp.181-88.

10. F. Wang, D.X. Ma, J. Zhang, S. Bogner, and A. Bührig-Polaczek: J. Mater. Process. Technol., 2014, vol. 214, pp. 3112-21.

11. H.E. Helmer, C. Körner, and R.F. Singer: J. Mater. Res., 2014, vol. 29 , pp. $1987-1996$.

12. G. Cam and M. Kocak: Int. Mater. Rev., 1998, vol. 43, pp. 1-44.

13. M.B. Henderson, D. Arrell, M. Heobel, R. Larsson, and G. Marchant: Sci. Technol. Weld. Join., 2004, vol. 9, pp. 13-21.

14. L.N Carter, M.M Attallah, and R.C. Reed: in Superalloys 2012, The Minerals, Metals \& Materials Society, Seven Springs, 2012, pp. $577-86$.

15. D. Dye, K.T. Conlon, P.D. Lee, R.B. Rogge, and R.C. Reed: in Superalloys 2004, The Minerals, Metals \& Materials Society, 2004, pp. 485-91. 
16. L.N. Carter, C. Martin, P.J. Withers, and M.M. Attallah: J. Alloys Compd., 2014, vol. 615, pp. 338-47.

17. G.P. Dinda, A.K. Dasgupta, and J. Mazumder: Mater. Sci. Eng. A, 2009, vol. 509, pp. 98-104.

18. J. Chen and L. Xue: Mater. Sci. Eng. A, 2010, vol. 527, pp. 7318-28.

19. L.E. Murr, E. Martinez, X.M. Pan, S.M. Gaytan, J.A. Castro, C.A. Terrazas, F. Medina, R.B. Wicker, and D.H. Abbott: Acta Mater., 2013, vol. 61, pp. 4289-96.

20. M. Gäumann, S. Henry, F. Cléton, J.D. Wagnière, and W. Kurz: Mater. Sci. Eng. A, 1999, vol. 271, pp. 232-41.

21. P. Heinl, C. Körner, and R.F. Singer: Adv. Eng. Mater., 2008, vol. 10 , pp. $882-88$.

22. P. Heinl, A. Rottmair, C. Körner, and R.F. Singer: Adv. Eng. Mater., 2007, vol. 9, pp. 360-64.

23. R.J. Seher, H.M. James, and G.N. Maniar: in Symphosium on Stereology and Quantitative Metallography, Atlantic City, 1972, pp. 119-37.

24. A. Wagner, B.A. Shollock, and M. McLean: Mater. Sci. Eng., 2004, vol. 374, pp. 270-279.
25. W. Kurz and D.J. Fischer: Fundamentals of Solidification, Trans Tech Publications, Switzerland, 1992.

26. A.K. Heckl: Universität Erlangen Nürnberg, Erlangen, 2011.

27. M. Ramsperger, L. Mújica Roncery, I. Lopez-Galilea, R.F. Singer, W. Theisen and C. Körner: Adv. Eng. Mater. 2015. DOI: 10.1002/adem.201500037.

28. I.M. Lifshitz and V.V. Slyozov: J. Phys. Chem. Solids, 1961, vol. 19 , pp. $35-50$.

29. R.A. MacKay and M.V. Nathal: Acta Metall. Mater., 1990, vol. 38 , pp. $993-1005$

30. R.E. Aune, L. Battezzati, R. Brooks, I. Egry, H.J. Fecht, J.P. Garandet, M. Hayashi1, K.C. Mills, A. Passerone, P.N. Quested, E. Ricci, F. Schmidt-Hohagen, S. Seetharaman, B. Vinet, and R. K. Wunderlich: in Superalloys 2005, E.A. Loria, ed., The Minerals, Metals \& Materials Society, 2005, pp. 467-76.

31. G.E. Fuchs: Mater. Sci. Eng. A, 2001, vol. 300, pp. 52-60.

32. B.C. Wilson, E.R. Cutler, and G.E. Fuchs: Mater. Sci. Eng. A, 2008, vol. 479, pp. 356-64. 